\title{
Professor Wolfgang Wagner, the President of ISPN (2018-2019)
}

\author{
Kyu-Chang Wang ${ }^{1}$
}

Received: 23 June 2020 / Revised: 23 June 2020 / Accepted: 24 June 2020 / Published online: 6 July 2020

(C) Springer-Verlag GmbH Germany, part of Springer Nature 2020

The President of International Society for Pediatric Neurosurgery (ISPN) (2018-2019) and Professor and Section Head of Pediatric Neurosurgery at the University Medical Center of Johannes Gutenberg University, Mainz, Germany, Wolfgang Wagner (Fig. 1) was born in 1954 in Ahrweiler at the northern part of Rheinland-Pfalz province in Germany (Fig. 2). He grew up and attended the elementary school and classic lyceum in Darmstadt (Fig. 3), which is not far from Mainz. In 1973, he started to study medicine at the Johannes Gutenberg University, Mainz, and graduated in 1979. He got the degree of medical doctor (Doctor medicinae) in 1980 with a thesis on lymphocyte transformation.

From 1981, he began to work as a resident in anesthesiology at the Vincenz-Hospital, Mainz, for 1 year. Thereafter, he spent 2 years (1982-1984) for research on human EEG at the II. Physiologic Institute, Johannes Gutenberg University in Mainz. Then, until 1996, he worked as a resident and a consultant neurosurgeon at the Department of Neurosurgery, Johannes Gutenberg University in Mainz. His research topics at this time were somatosensory evoked potentials (SSEP), diagnosis of brain death, and intraoperative neurophysiological monitoring.

In 1996, he got the qualification for professorship (Doctor medicinae habilitatus) with a professorial thesis on SSEP in coma and brain death, an interesting topic, and became a private lecturer ("Privatdozent") in neurosurgery. He moved to Greifswald in northeast Germany (Fig. 3) and worked as a consultant neurosurgeon and private lecturer at the Department of Neurosurgery at Ernst-Moritz-Arndt University for more than 4 years. During this period, his main

Kyu-Chang Wang

kcwang@snu.ac.kr

National Cancer Center, Goyang, Republic of Korea clinical and scientific activities focused on pediatric neurosurgery, tumor surgery, neuronavigation, neuroendoscopy, and stereotactic and functional neurosurgery.

In 2000, he moved back to Mainz as the head and private lecturer of the Pediatric Neurosurgery at the Department of Neurosurgery, University Hospitals of the Johannes Gutenberg University. He had interests in neuronavigation, neuroendoscopy, ventriculostomy in young infants, and development of new techniques in craniosynostosis surgery.

During this time in Mainz until his retirement in 2020, he had many academic and social achievements. From 2002 to 2013, he served as a member of the Scientific Committee of the German Society for Neurosurgery (Deutsche Gesellschaft für Neurochirurgie, DGNC). Since 2004, he contributed to the Foundation for Neurosurgical Research of the German Society for Neurosurgery as the secretary. He became a full professor in 2004 and served as the acting chairman of the neurosurgical department in Mainz from 2008 for 3 years.

In the German Society for Neurosurgery, he has contributed to the Section of Pediatric Neurosurgery for a long time. From 2007 to 2015, he held the position of Speaker of the Section of Pediatric Neurosurgery of the German Society for Neurosurgery. The group of German pediatric neurosurgery has a number of famous world leading scholars in addition to Professor Wagner (Fig. 4). Many ISPN members remember the leading representatives of the German pediatric neurosurgery group shown on the poster exhibited at ISPN 2013 Mainz (Fig. 5).

He also played a major role in European Society for Pediatric Neurosurgery (ESPN) as Chairman and Cochairman of the Membership Committee and a member of the Nominating Committee from 2010 to 2018.

Wolfgang made his debut at ISPN 2000 Istanbul as a keyboard player rather than a scientist (Fig. 6). He became a member of ISPN 2 years later. Since then, he has shown enthusiastic activities. In 2006, he joined the editorial board of 


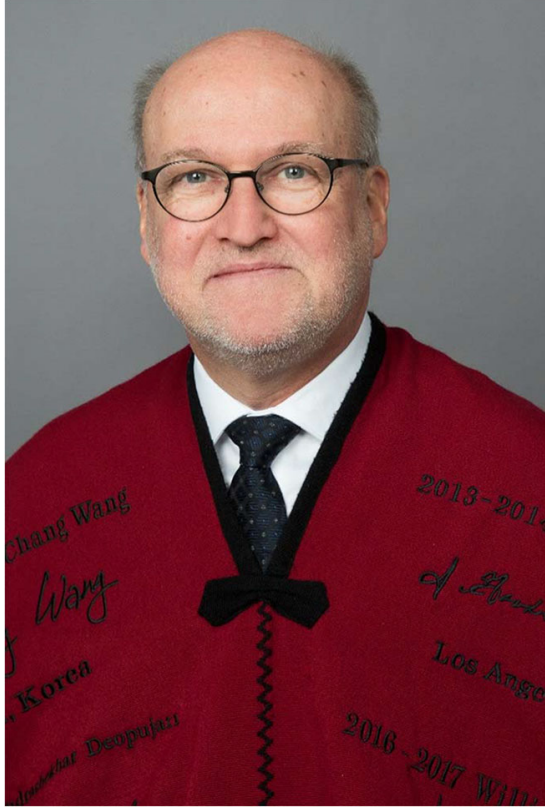

Fig. 1 The President of ISPN (2018-2019), Professor Wolfgang Wagner
Child's Nervous System, the official journal of the ISPN. With recognition of his contribution to ISPN and the leadership in his national, continental, and global pediatric neurosurgical societies, he could host the 41 st annual scientific meeting of ISPN at Mainz in 2013. It was the second annual scientific meeting of ISPN held in Germany, next to the meeting of ISPN 1976 Würzburg. All the participants of ISPN 2013 Mainz remember the logo and the venue of the meeting in 2013 (Fig. 7). Then, he began to serve as a member of the ISPN Executive Board (2013-2014 Chairman of the Membership Committee; 2014-2016 Cochairman and Chairman of the Communication Committee; 2017-2018 President Elect) and became the President. In 2018, he received the Poncho from the stepping-down President Professor Graham Fieggen in Tel Aviv (Fig. 8). He is the second ISPN President from Germany, next to Professor Karl Bushe who had the same position from 1974.

During his academic life as a pediatric neurosurgeon, his scientific interests are hydrocephalus, particularly shunt independency, slit ventricle syndrome and endoscopy, and craniosynostosis. He published more than 130 articles and book

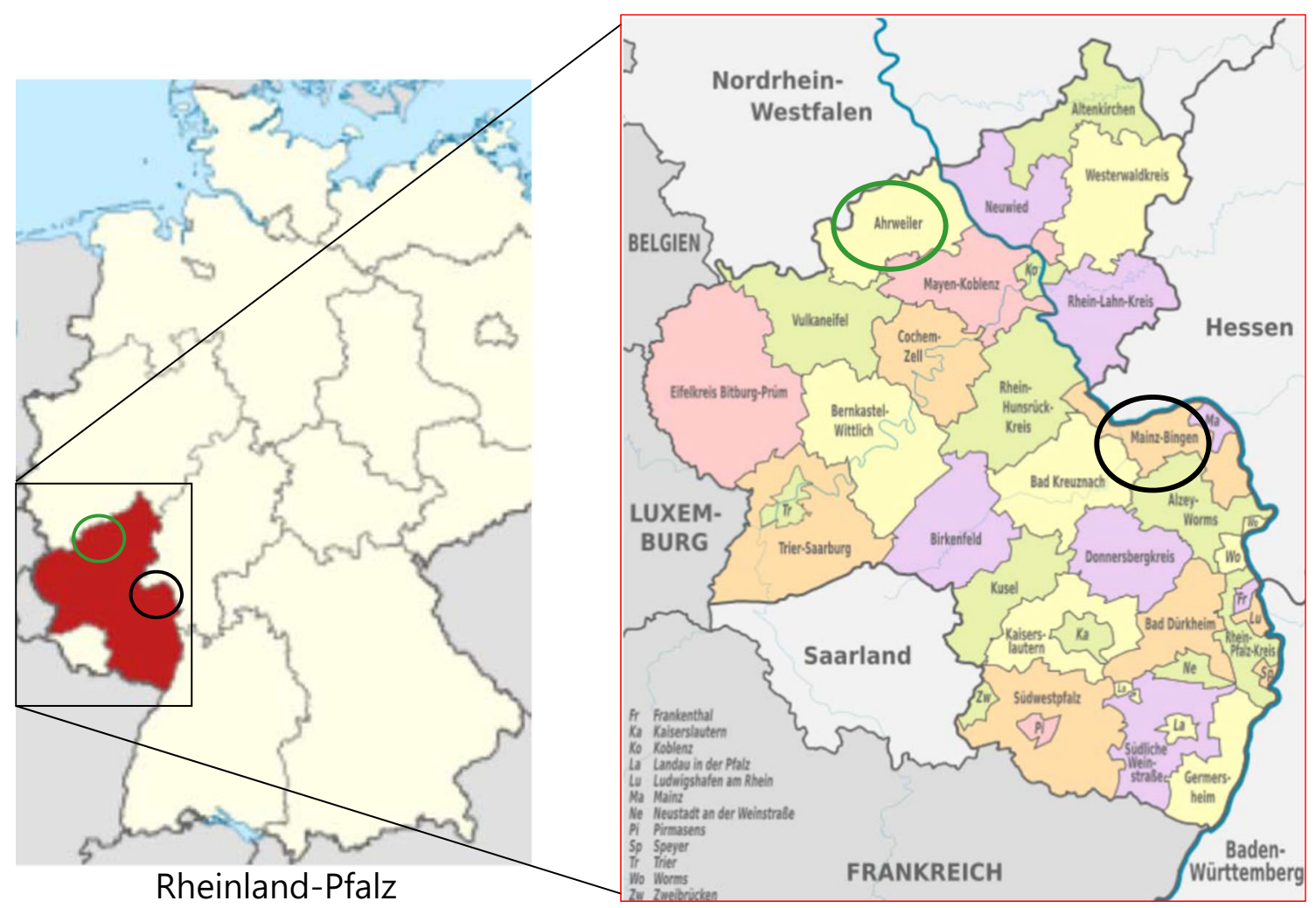

Fig. 2 The birthplace of Professor Wagner, Ahrweiler at the northern part of Rheinland-Pfalz province in Germany (green circle) and Mainz (black https://m.post.naver.com/viewer/postView.nhn?volumeNo= 27895319\&memberNo=5935639\&vType=VERTICAL (left) and https:// cafe.naver.com/o2forrun/774 (right) 


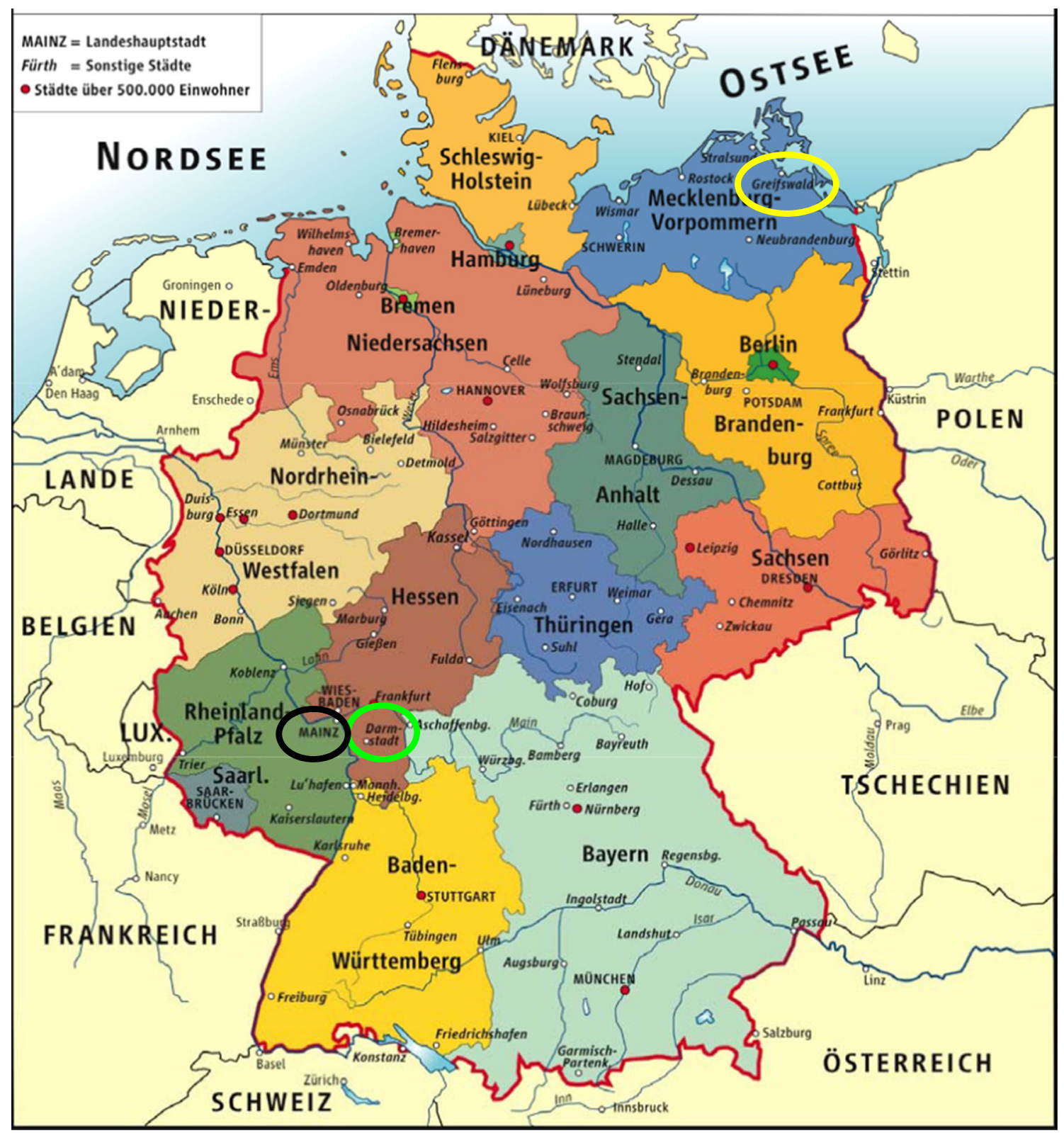

Fig. 3 Mainz (black circle), Darmstadt where Professor Wagner has grown up (light green circle), and Greifswald in northeast Germany (yellow circle) where he spent 4 years as a consultant neurosurgeon and private lecturer. modified from https://cafe.naver.com/kmurudwpgkrtk/11

chapters and presented nearly 300 papers at the scientific meetings. His academic memberships and the editorial activities for scientific journals are listed in Tables 1 and 2.

Wolfgang married Ulrike Wagner in 1982 and has three children with two grandchildren leading a harmonious family life (Fig. 9). He planned a postretirement world tour with
Ulrike, one of their dreams. When the pandemic of Covid19 fades down, they will start to realize their dreams.

I have seen Wolfgang around 2000 at an ISPN meeting. He has stepped similar path with me: born, graduated from a medical school, married in similar years, similar positions in domestic pediatric neurosurgical societies as one of the 
Fig. 4 German Pediatric Neurosurgery Working Group at Mainz in 2011 during a course organized by Professor Martina Messing-Jünger. Pink circle,

Professor Wagner

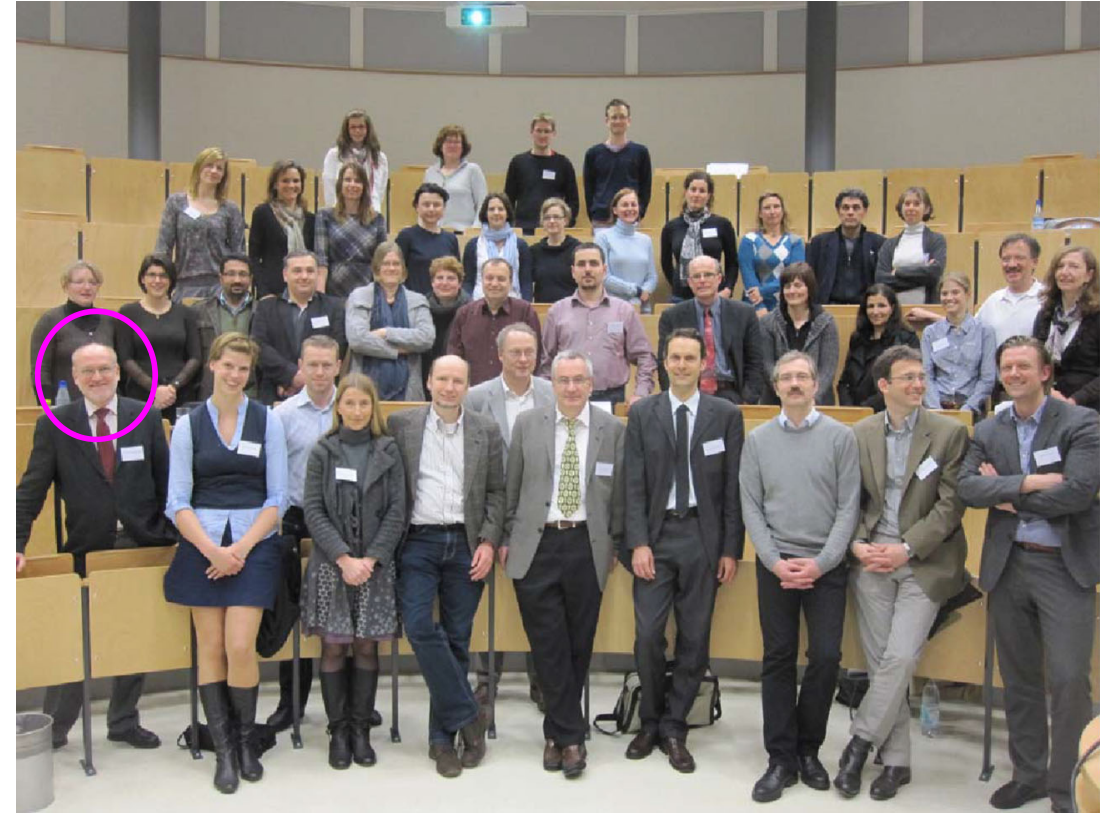

leading representatives of the second-generation pediatric neurosurgeons in each country, and similar positions in ISPN. Furthermore, both of us have baldheads (Fig. 10).
Professor Wolfgang Wagner showed active participation and contribution to ISPN as a member in the meeting, as an officer, as the host of a meeting, and as the President. He is considerate, against to something wrong,

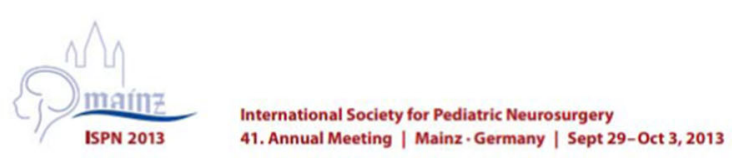

The "Family" of Pediatric Neurosurgeons in Germany
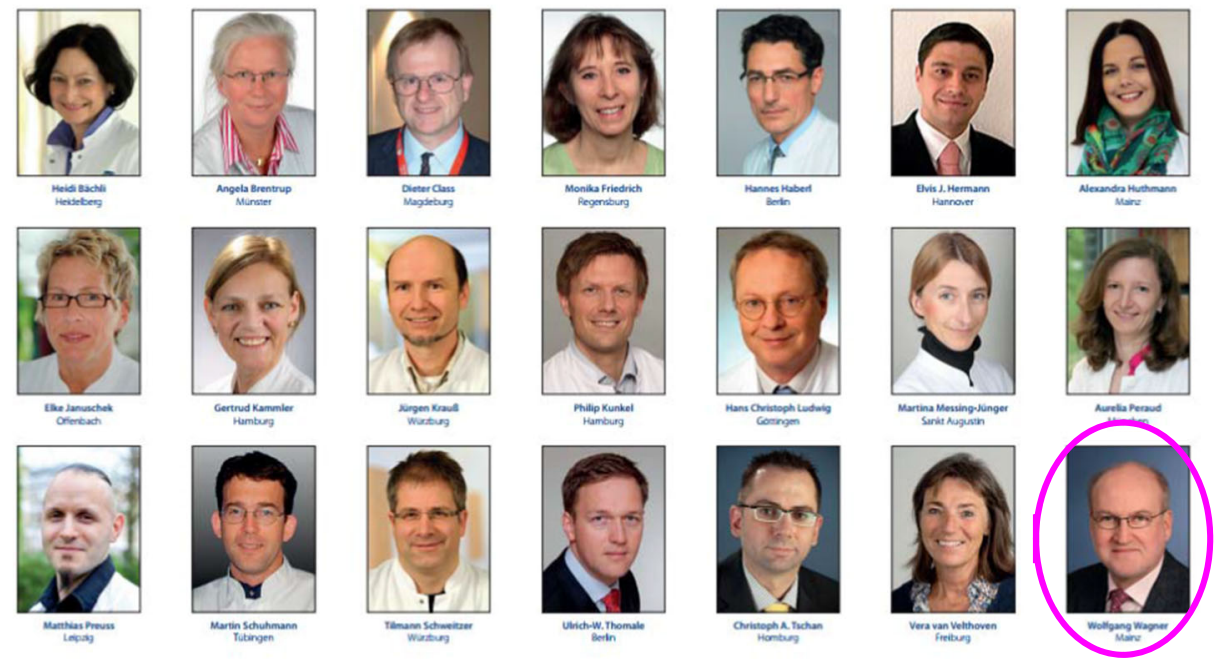

Fig. 5 "The family of pediatric neurosurgeons in Germany" posted at ISPN 2013 Mainz. Pink circle, Professor Wagner 
Fig. 6 Professor Wagner made his debut at ISPN 2000 Istanbul as a keyboard player. Pink circle, Professor Wagner; blue circle, Professor Mutluer, the host of the annual meeting
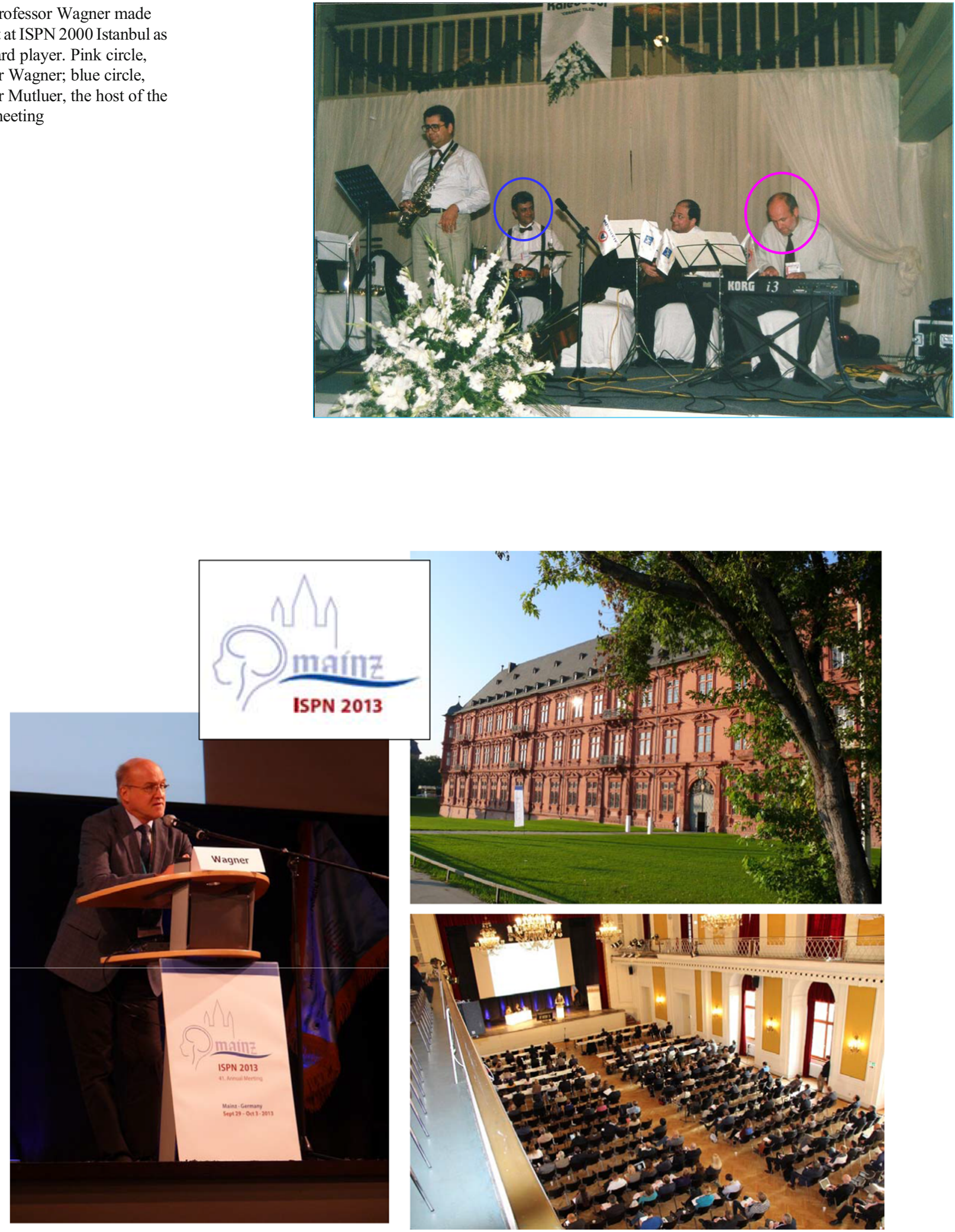

Fig. 7 Logo, host, and venue of ISPN 2013 Mainz 
Fig. 8 The Poncho, a symbol of the ISPN President, was handed over to Professor Wagner by stepping-down President Professor Fieggen at ISPN 2018 Tel Aviv
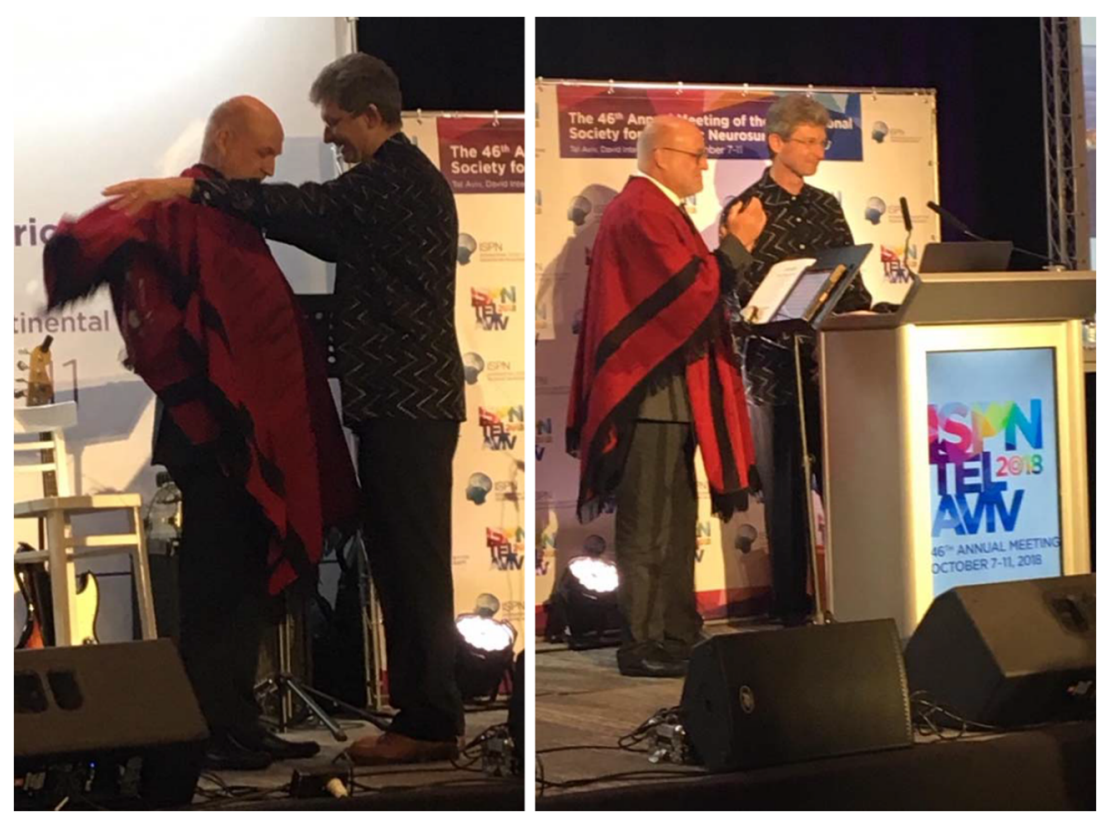

Table 1 Memberships in academic societies

German Society for Physiology (DPG) since 1986

German Society for Clinical Neurophysiology (DGKN) since 1989

German Society for Neurosurgery (DGNC) since 1993

French Speaking Society for Neurosurgery (Société de Neurochirurgie de Langue Française, SNCLF) since 1993

German Society for Endoscopic Neurosurgery and Neuronavigation (later: Section for Neuroendoscopy, Neuronavigation and Intraoperative Imaging of the DGNC) since 1994

International Society for Pediatric Neurosurgery (ISPN) since 2002

European Society for Pediatric Neurosurgery (ESPN) since 2008

Table 2 Reviewer activities for scientific journals

Fig. 9 Professor Wagner with his wife Ulrike at the wedding ceremony in 1982 and his family in 2019

Acta Neurochirurgica

Child's Nervous System (Member of the Editorial Board since 2006)

Clinical Neurophysiology

Neurosurgery

Neurosurgical Reviews

Minimally Invasive Neurosurgery

Zentralblatt für Neurochirurgie (Central European Neurosurgery)

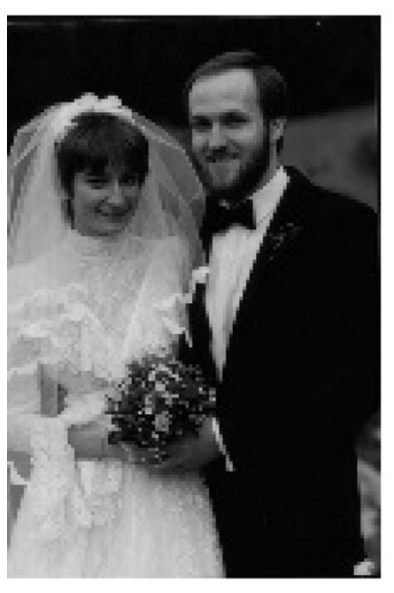

1982

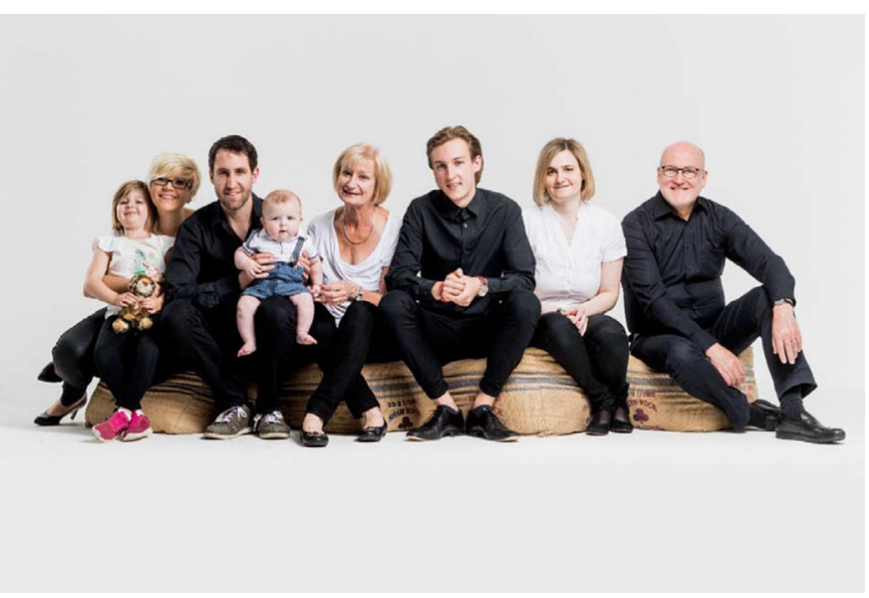

2019 


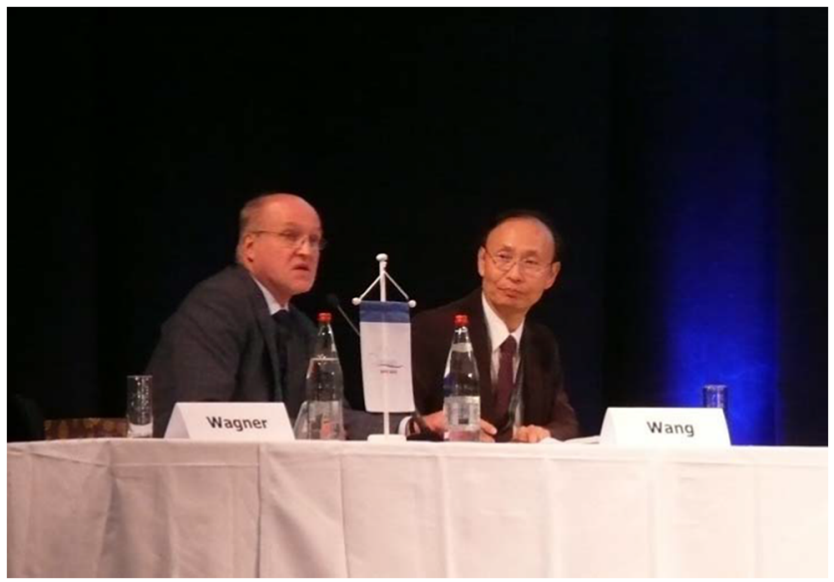

involved in, especially the ISPN, are indebted to him for their substantial and fruitful growth.

\section{Compliance with ethical standards}

Fig. 10 Professor Wagner chaired the starting session of ISPN 2013 Mainz with me

has outstanding leadership, and always seeks for improvements. The pediatric neurosurgical societies which he had

Conflict of interest The corresponding author states that there is no conflict of interest.

Publisher's note Springer Nature remains neutral with regard to jurisdictional claims in published maps and institutional affiliations. 